\title{
Application of pseudo-acoustic inversion technique in identifying sandstone and mudstone of coal seam roof and floor
}

\author{
Wenxi Wei, Suzhen Shi, Chao Sun, Shijie Li \\ State Key Laboratory of Coal Resources and Safe Mining \\ China University of Mining \& Technology (Beijing) \\ Beijing, China \\ 1534177078@qq.com
}

\begin{abstract}
The coal bed methane (CBM) content is often relatively high where the immediate roof and floor of the coal seam are mudstone. In order to predict the CBM rich region, position of coal seam roof and floor and distribution of sandstone and mudstone are based on acoustic wave impedance inversion and pseudo-acoustic inversion technique through seismic data and well logging data analysis. This method provides a basis for the exploration and development of the CBM. First of all, the position of coal seam roof and floor can be acquired accurately in the acoustic wave impedance inversion profile due to low acoustic impedance values of coal. Pseudo-acoustic curve is constructed by natural gamma curve. In the pseudo-acoustic inversion profile which has high lateral continuity, the mudstone shows high values, the sandstone shows low values, so it is possible to characterize the sandstone and the mudstone when the range is acquired though data analysis. The application in practice shows that, the inversion method is better than conventional one in resolution and achieved good results in practice.
\end{abstract}

Keywords—coal seam roof and floor; sandstone and mudstone; pseudo-acoustic curve; logging constrained inversion

\section{INTRODUCTION}

The coal bed methane (CBM) has attracted more and more attention as a new clean energy. It has a great significance to keep China's sustainable development of the national economy and improve the energy structure of our country. At present, a variety of geophysical technology is being applied. Seismic exploration can provide lithological information of coal seam. So it has been widely used in the CBM exploration for its high density and low cost [1]. The lithology of coal seam roof and floor is one of the main controlling factors for the CBM rich region in researching seismic geological parameters. The CBM content is higher in general when the roof or floor is mudstone for its good sealing ability. In contrast, the content is relatively poor if it is sandstone. Therefore, it is necessary for the CBM exploration to predict the lithology of coal seam roof and floor.

Pseudo-acoustic impedance inversion application was mainly based on the Gardner and Faust formula to make curves to predict reservoir in the past [2-5]. This paper is to make curve-fitting about the natural gamma curve which reflects reservoir physical property and time-deep relationship of the acoustic curve to reconstruct a new curve for inversion. Compared to formula estimation and statistical curve-fitting method, the new curve can reflect more details about lithology due to the sensitive of natural gamma curve. Therefore, we can identify the lithology when combining with geological and drilling information.

\section{THEORY AND METHOD}

According to the principle of natural gamma logging, it can be known that natural gamma value is measured by the number of radioactive material. Radioactivity is mainly increased with the increase of shale content when the layer only contains sand and shale. Natural gamma curve has little relations with rock porosity, property of the fluid in pores, formation water and mud salinity. Therefore, it is better than acoustic curve in lithology identification, resolution and stability. So the natural gamma curve is chose to reconstruct.

The steps of pseudo-acoustic inversion: first of all, pretreat for different curve. Then make curve-fitting about the natural gamma curve and time-deep relationship of the acoustic curve to reconstruct a new curve for inversion. Through wavelet extraction, well-seismic calibration, initial model establishment, inverse analysis and other steps, the impedance inversion is processed.

\section{A. Logging curve pretreatments}

Filed environment and different acquisition parameters can lead to a difference between similar type of well logging curves, which seriously affected the formation interpretation and seismic reservoir inversion results. Expect that, because of the value relatively low, natural gamma logging curve need to be adjusted to the range of acoustic curve before reconstructing the curve. So it is necessary to carry out standardized processing to the curve to eliminate the influence of different acquisition parameters on the logging results. This step can make all wells into the same dimension. The method of intersection analysis of frequency histogram is used to deal with it. 


\section{B. Pseudo-acoustic and Density CurveConstructions}

Based on well logging, seismic and geological comprehensive research, the pseudo-acoustic curve is constructed to reflect the geological characteristics for solving the geological and the inversion problem. The natural gamma curve is selected to distinguish the sandstone and mudstone.

First, we need to extract time-depth relationship. The synthetic seismic trace is formed by the convolution of the acoustic wave, density curve and seismic wavelet. By comparing with the real seismic trace, the formation lithology interface is calibrated and matched. After the calibration, the reasonable time-depth relationship is obtained, and we can extract it. Then pseudo-acoustic curve with time-depth relationship is formed by reconstructing time-depth relationship and natural gamma curve. The last step is building density curve. The value of shale content shows high and the sandstone shows low in the natural gamma curve. However, in the density curve, the density of mudstone is less than the density of sandstone, so using the density curve will reduce the resolution of sandstone and mudstone in the process of forming inversion. Therefore, the density curve is defined as a constant value, which can directly reflect the variation of the sandstone and mudstone.

\section{Initial Model Establishments}

The establishment of the initial model mainly depends on the continuous change of the seismic interface information and vertical log data. Seismic data record continuously the lateral variation of the interface and logging data can reveal the details of the lithology changes in vertical. It is necessary to obtain the actual geological conditions combining with them. The initial model is actually forming a smooth closed entity model in the constraints of the geological concept.

\section{Inversion Analyses}

P-wave impedance inversion can be got by using $\mathrm{p}$-wave and density curve to invert. The value will be different between coal seam and its surrounding rock since coal seam shows low values. So the position of coal seam roof and floor can be obtained. Pseudo-acoustic impedance inversion can use pseudo-acoustic curve and the density curve to get. Then we can get the range of sandstone and mudstone by analyzing pseudo-acoustic impedance inversion data volume and logging data. At last we can characterize lithology in coal seam roof and floor.

\section{EXAMPLES}

\section{A. The Situation in the Study Area}

We make study area L as an example. The study area is located in the northwest of Luliang City in Shanxi Province, close to the Yellow River. The study area also belongs to Firstorder tectonic units of Jin-west flexure belt in north-central Ordos's basin. The area is a western-leaning monoclinal structure that the east is high and the west is low. Except that, the dip angle is small and the fault is not development. The coal seam develops in Taiyuan and Shanxi group. $4^{\#}$ and $8^{\#}$ coal seam are primary mineable coal bed. The distance between two coals is about 30 to 90 meters.

\section{B. 2 Lithology Distribution Characteristics of Coal Seam Roof and Floor}

P-wave impedance inversion profile (Fig. 1) in study area can be acquired by using logging constrained inversion. The color in the figure represents impedance values. It is different between coal seam and its surrounding rock in p-wave impedance inversion profile since coal seam shows low values, the green part in Fig. 1. The upper and lower section on coal seam is the position of the roof and floor (Fig. 2). The mudstone and sandstone can be divided in this section in the pseudo-acoustic inversion profile.

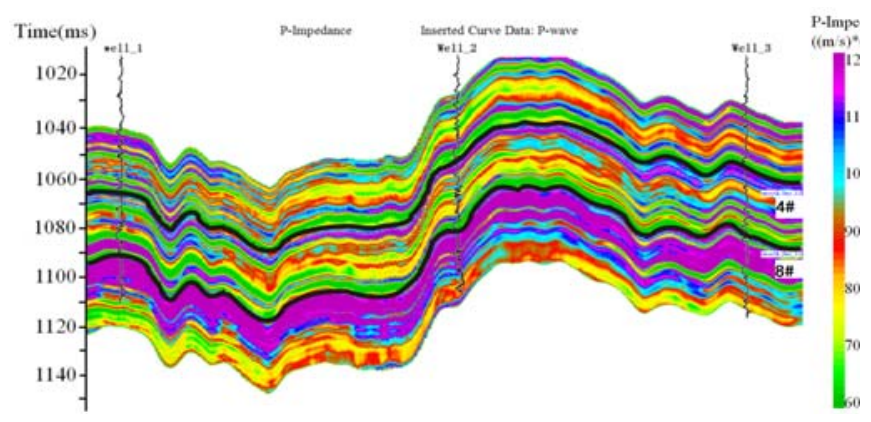

Fig. 1. P-wave impedance inversion profile.

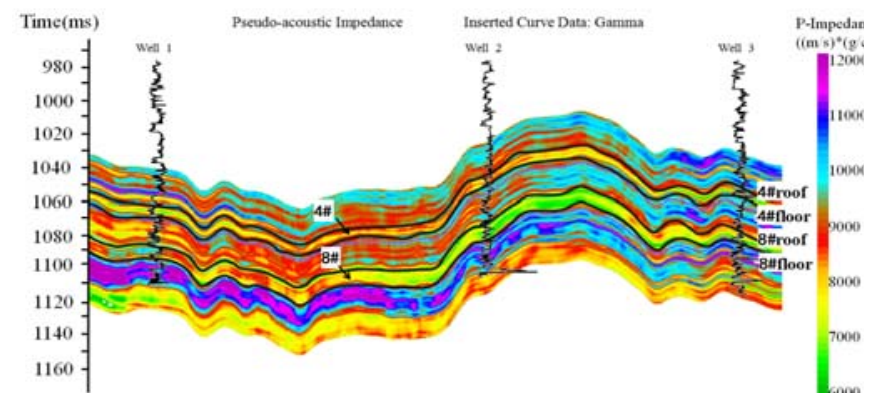

Fig. 2. Pseudo-acoustic impedance inversion profile.

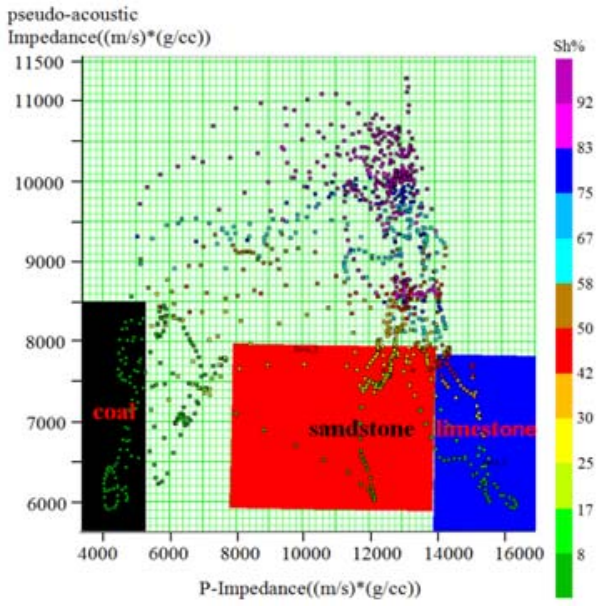

Fig. 3. Cross-plot analyses for well_1. 
Fig. 3 displays p-wave impedance and pseudo-acoustic impedance cross-plot analysis for well_1 from $4^{\#}$ coal seam roof (about 3 to 5 meters) to $8^{\#}$ coal seam floor (about 6 to 11meters). The horizontal axis shows p-wave impedance and longitudinal axis shows pseudo-acoustic impedance, the color displays for shale content. Black section represents the coal seam that pseudo-acoustic impedance value is less than 8500 $(\mathrm{m} / \mathrm{s})^{*}(\mathrm{~g} / \mathrm{cc})$ and $\mathrm{p}$-wave impedance value is less than 5300 $(\mathrm{m} / \mathrm{s}) *(\mathrm{~g} / \mathrm{cc})$. (Shale content $<17 \%)$ Red section represents the sandstone that pseudo-acoustic impedance value is less than $7900(\mathrm{~m} / \mathrm{s})^{*}(\mathrm{~g} / \mathrm{cc})$ and $\mathrm{p}$-wave impedance value is more than $7800 \mathrm{~m} / \mathrm{s}^{*} \mathrm{~g} / \mathrm{cc}$ and less than $13800(\mathrm{~m} / \mathrm{s}) *(\mathrm{~g} / \mathrm{cc})$. (Shale content $<25 \%)$ Blue section represents the limestone that pseudoacoustic impedance value is less than $7700(\mathrm{~m} / \mathrm{s})^{*}(\mathrm{~g} / \mathrm{cc})$ and $\mathrm{p}-$ wave impedance value is more than $13800(\mathrm{~m} / \mathrm{s})^{*}(\mathrm{~g} / \mathrm{cc})$. (Shale content $<25 \%$ ) The other section is mainly represents the mudstone and other lithology. The lithology in cross-plot is match with lithological column in the same depth (Fig. 4).

Fig. 5 shows p-wave impedance inversion of $4^{\#}$ coal seam roof. The color represents the p-wave impedance value. Some part of mudstone can be characterized. But most of lithology cannot be divided. So the mudstone and sandstone cannot be characterized by using p-wave impedance inversion method. Fig. 6 shows pseudo-acoustic impedance inversion of $4^{\#}$ coal seam roof. The color represents the pseudo-acoustic impedance value. It shows the change of coal seam roof lithology. The black line in the figure shows that the yellow-green areas is for the sandstone area, purple area is for the mudstone area, blue and red area is for other lithology such as mudstone or siltstone. This layer does not contain the limestone. We can see that, the lithology has a clear banding distribution. The mudstone is mainly distributed in the northeast of the coal seam roof, gradually transition into the sandstone from northeast into southwest. Compared with the Fig. 5, the lithology classification is clearer. So the pseudo-acoustic impedance inversion can provide the basis for the CBM prediction. It shows that single seismic geological factors to predict CBM enrichment region has certain limitations because of various factors affecting the CBM enrichment. All the factors need to be considered in practice application.

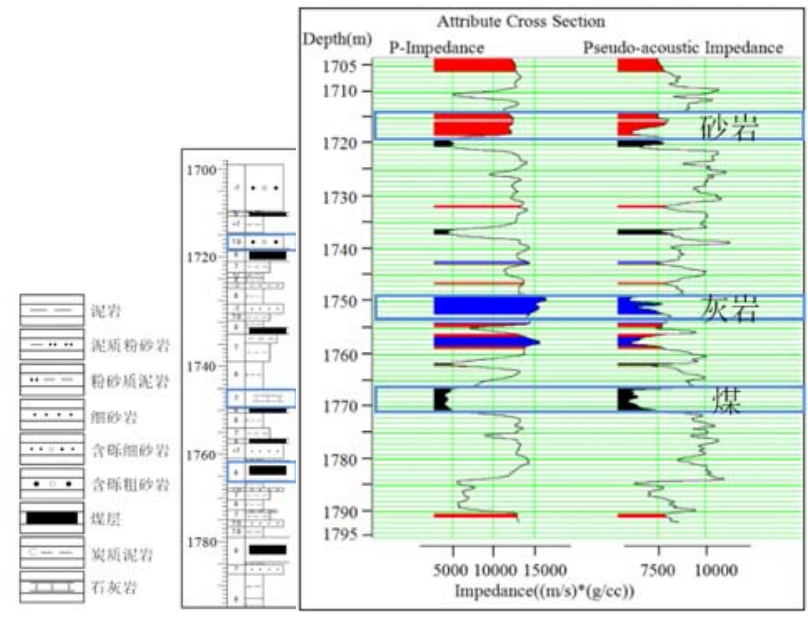

Fig. 4. he comparison of lithology in cross-plot and lithological column.

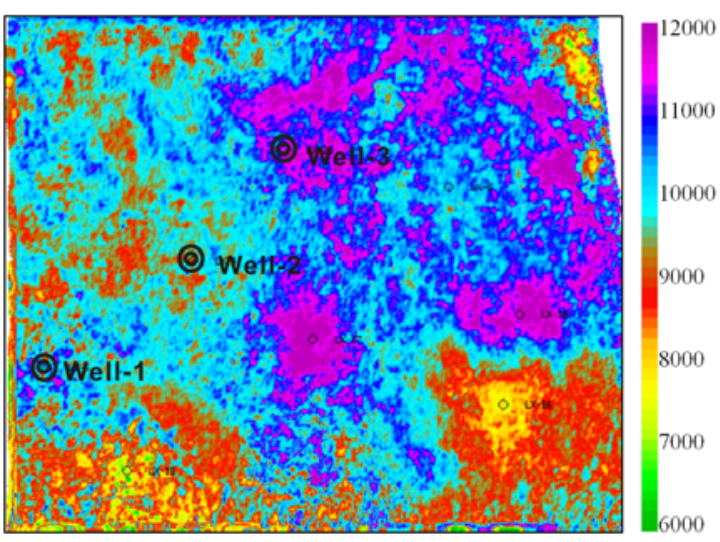

Fig. 5. P-wave inversion of $4^{\#}$ coal seam roof.

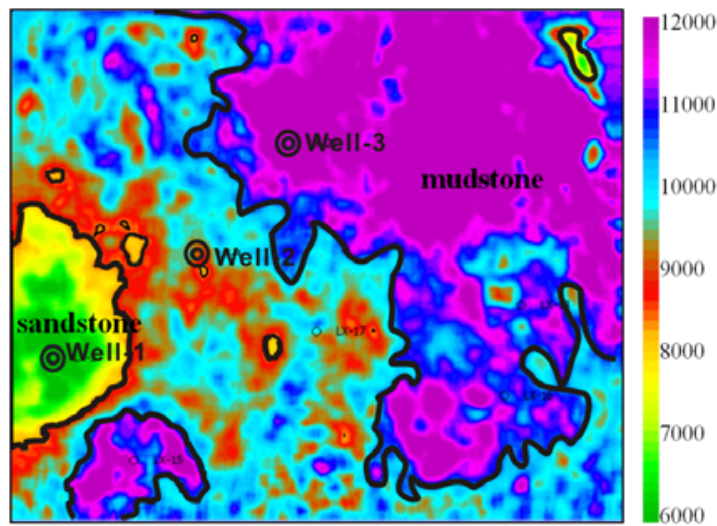

Fig. 6. Pseudo-acoustic inversion of $4^{\#}$ coal seam roof.

Comparing the well lithology logging interpretation chart, we can confirm the reliability of inversion results. Combined with geological and drilling information, it is reasonable to identify the lithology of coal seam roof and floor by using pseudo-acoustic impedance inversion. The method provides a geological basis for CBM well selection and layout of wells.

\section{CONCLUSIONS}

When the acoustic wave curve cannot reflect the lithology, physical properties or other information clearly, it is easier to use the pseudo-acoustic curve instead of it. Pseudo-acoustic impedance inversion can be realized by the correcting the logging data, extracting the time-depth relationships that is finished the calibrating, reconstructing with the natural gamma, establishing the initial model, and pseudo-acoustic impedance inversion can be realized.

In the inversion profile which has high lateral continuity, the p-wave impedance inversion can acquire the position of the roof and floor due to the low value of coal seam. The mudstone shows high values and the sandstone shows low values in pseudo-acoustic impedance inversion profile, So it is possible to characterize the lithology when the range is acquired though data analysis.

The application in practice shows that, the inversion method is better than conventional one in resolution and 
achieved good results in practice. It can predict the CBM as a reference method. However, it need to be analyzed the multiple solution of seismic data in practice applications.

\section{ACKNOWLEDGMENT}

We are grateful for financial supports from National Natural Science Funds Coal Joint Project (U1261203), National Key Scientific Instrument and Equipment Development Program (2012YQ030126), Shanxi Natural Science Funds Project (2013012001).

\section{REFERENCES}

[1] L Shi, CJ Wang, "Do high resolution inversion by using simulated ac curve," Journal of Southwest Petroleum Institute, vol. 26, pp. 18-20, October 2004.

[2] YX Wang, DZ Tang, JH Gong, YX Zhu, YH Ji., “Application of quasiacoustic inversion technology to reservoir prediction-a case study of the cretaceous in shengbei area of thetaibei sag, thetuha basin,” Petroleum Geology \& Experiment, vol. 26, pp. 303-307, June 2004.

[3] BH Liu, SL Zheng, D Guan, "Broadband constrained impedance inversion on pseudo- acoustic curve and its application in reservoir prediction,” Progress in Exploration Geophysics, vol. 28, pp. 416-421, December 2005.

[4] HS Zha, ZC Gan, WJ Liu, ZP Bian, CY Xu, Z Yu, YX Gai, "Latest discussion on natural gamma-ray pseudo-acoustic curve construction technology,” Coal Geology of China, vol. 26, pp. 58-62, May 2014.

[5] ZF Yang, RF Tian, X Xiao, Y Hu, QZ Chen, "The application pseudoresistivity reconstruction to identify oil layers in lithologic reservoir," Science Technology and Engineering, vol. 14(07), pp. 117-120, March 2014 